\title{
EVALUATION OF NOURISHMENT SCHEMES BASED ON LONG-TERM MORPHOLOGICAL MODELING
}

\author{
Nicholas Grunnet ${ }^{1}$, Sten Esbjørn Kristensen ${ }^{1,2}$, Nils Drønen ${ }^{1}$ \\ Rolf Deigaard ${ }^{1}$, Caroline Tessier ${ }^{3}$ and Nicolas Forain ${ }^{4}$
}

\begin{abstract}
A recently developed long-term morphological modeling concept is applied to evaluate the impact of nourishment schemes. The concept combines detailed two-dimensional morphological models and simple one-line models for the coastline evolution and is particularly well suited for long-term simulation. This hybrid concept is here applied to study the decadal morphological evolution of several nourishment scenarios in Dunkirk, France. The morphological simulations successfully allowed identifying the impact of beach versus shoreface nourishment scenarios on the background morphological behavior of the study site. This study strongly indicates that the hybrid model may be used as an engineering tool to predict shoreline response following the implementation of a nourishment project.
\end{abstract}

Keywords: morphological modeling; nearshore bars, beach nourishment

\section{INTRODUCTION}

The recently developed long-term morphological modeling concept proposed in Kristensen et al. (2010) is used in order to evaluate the impact of nourishment schemes. The concept tries to bridge the gap between existing detailed two-dimensional morphological models and simple one-line models for the coastline evolution and hence is referred to as 1-D hybrid modeling. A first promising application of the hybrid model concept as an engineering tool for predicting effects of offshore breakwaters was given in Drønen et al. (2011) and Kristensen et al. (2012, 2013a). The hybrid morphological model has now also been used to simulate morphological response to groyne fields (Kristensen et al. 2013b). This paper provides an additional application of the morphological modeling concept in relation to the design and optimization of beach and shoreface nourishment projects. The concept is particularly well suited for long-term simulation and is here applied to study the decadal morphological evolution of several nourishment scenarios in Dunkirk, France.

The Dunkirk East Harbor breakwaters and dredged navigation channel act as sediment traps which effectively block the littoral drift to the downdrift beaches. Erosion has been ongoing for decades along these beaches backed by dikes and has now resulted in a severe marine flooding hazard of the lowlying and densely-populated hinterland. Yearly maintenance dredging is necessary to ensure a safe navigation depth. The high-quality dredged medium sand has traditionally been disposed offshore and thereby lost from the littoral zone. Aware of the interests which could be served by supplying this material onto the eroding beaches, the harbor authorities now wish to implement a scheme that both provides coastal protection to the threatened dikes and acts as a sand by-passing system past the harbor. DHI was commissioned to design such a scheme.

\section{STUDY AREA}

\section{Environmental setting}

Dunkirk is located on the southern North Sea part of the English Channel (see Figure 1). Waves are incident from both the North Sea and the North Atlantic Ocean. Ocean waves that have propagated through the English Channel are somewhat attenuated. The mean annual significant offshore wave height at the $-20 \mathrm{~m}$ isobath is about $0.9 \mathrm{~m}$ and the mean annual significant offshore wave period is about $6 \mathrm{~s}$. During severe autumn and winter storms significant wave heights increase up to 4 to $5 \mathrm{~m}$. A corresponding wave rose is also illustrated in Figure 1.

Tides along the coast at Dunkirk are semidiurnal and macrotidal with a neap tidal range of about $3.5 \mathrm{~m}$ and a spring tidal range of about $5.5 \mathrm{~m}$. The flood (ebb) tidal flow is in an ENE (WSW) direction. Associated tidal currents are slightly stronger during flood than during ebb and tidal ellipses are basically oriented parallel to the shore and are flat and rectilinear. At spring tide, the flow velocities at the surface are in the order of $1.4 \mathrm{~m} / \mathrm{s}$. Wind-driven currents are generated in the study area as the coastline is oriented parallel to the predominant westerly winds.

The seabed in the shoreface consists mainly of fine to medium sands, ranging from 125 to $500 \mu \mathrm{m}$. The beach face is characterized by fine sands ranging from 170 to $200 \mu \mathrm{m}$. Beach face slopes are typically ranging from $1 / 70$ to $1 / 200$.

\footnotetext{
${ }^{1}$ Dept. of Coastal and Estuarine Dynamics, DHI, Agern Allé 5, DK-2970 Hørsholm, Denmark

2. Dept. of Mechanical Engineering, Technical University of Denmark, DK-2800 Lyngby, Denmark

${ }^{3} \mathrm{DHI}, 2 / 4$ rue Edouard Nignon, 44372 Nantes, France

${ }^{4}$ Grand Port Maritime de Dunkerque, Terre-plein Guillain, 59386 Dunkerque, France
} 


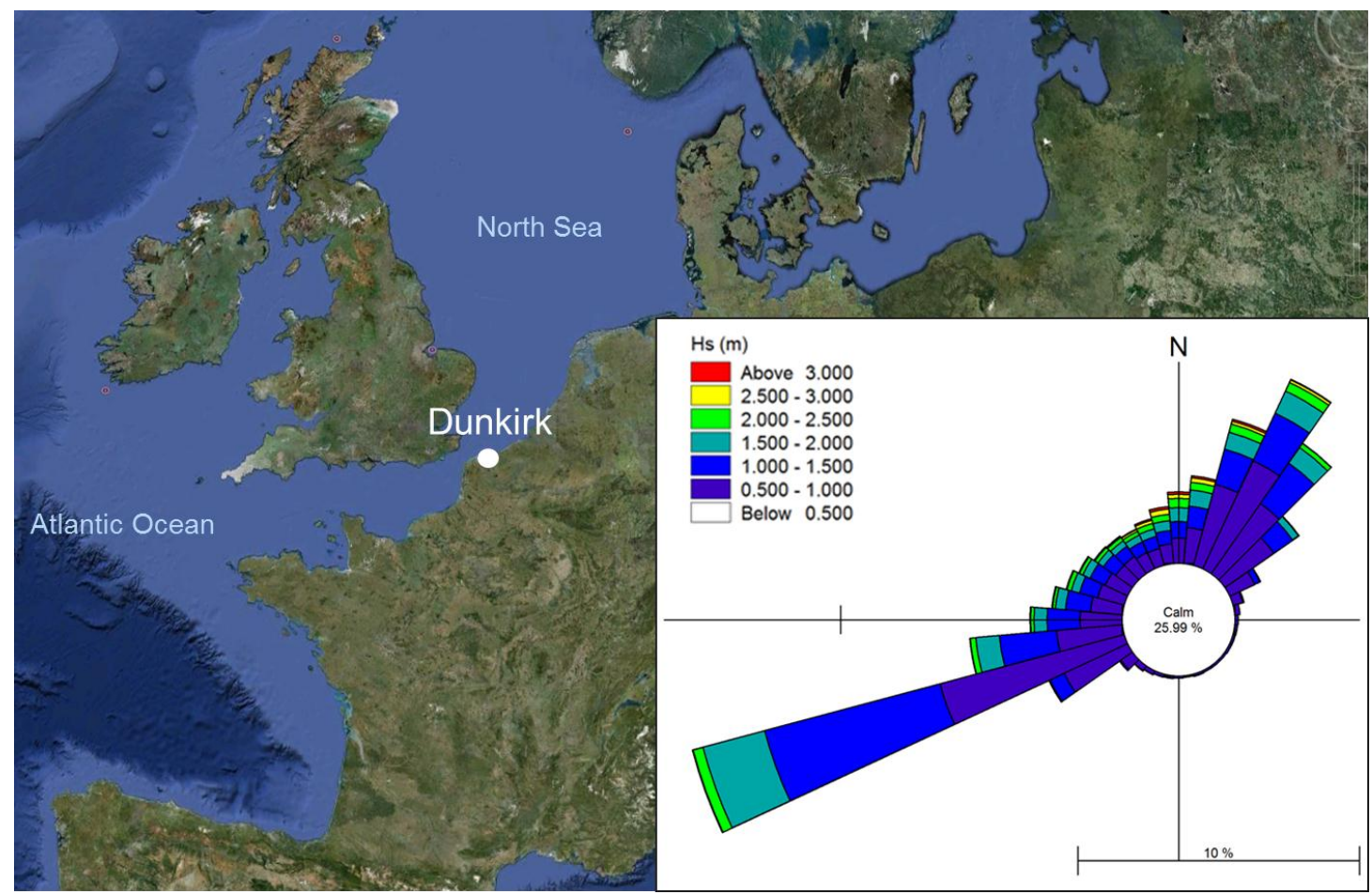

Figure 1. Location of study site and 1979-2002 wave rose off Dunkirk.

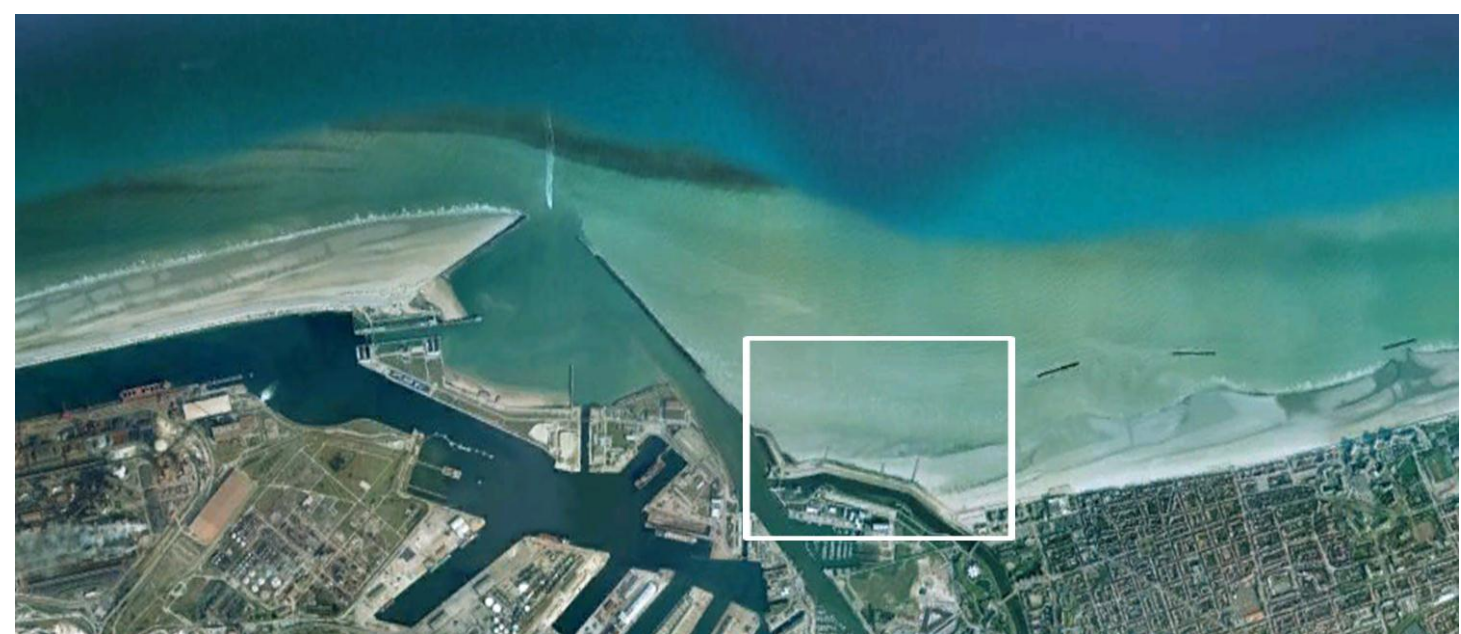

Figure 2. Aerial view of Dunkirk East Harbor with indication of the study area (white box).

\section{Complex morphodynamic setting}

The study area is located immediately east of the eastern breakwater of Dunkirk East Harbor and is characterized by the presence of numerous coastal structures (groins, breakwaters and dikes), dredged channels and offshore sand banks.

The harbor breakwaters and dredged navigation channel act as sediment traps which effectively block the littoral drift to the downdrift beaches to the east of the harbor entrance. The updrift impoundment of sediment and offshore disposal of dredged material has resulted in coastal erosion for decades along the beaches east of the harbor. Figure 2 shows groins and detached breakwaters that are in place to mitigate the erosion. In order to prevent marine flooding of the low-lying and denselypopulated hinterland, the beach is also backed by a coastal dike (located inside the white box in Figure 2). The chronic lowering of the beach face in front of the coastal dike is threatening the safety of the dike and presents a severe marine flooding hazard. Comparison of historical bathymetric surveys yields an erosion on the order of $10,000 \mathrm{~m}^{3} / \mathrm{yr}$ on the beach face seaward of the coastal dike.

The offshore bathymetry is characterized by of a group of irregular sand banks called the Flemish banks. These sand banks have a wavelength between 1 and $10 \mathrm{~km}$, and they are up to several tens of meters high. The sand banks are formed by tide-seabed interactions and are actively maintained by the tidal regime. In the vicinity of Dunkirk these banks are found to be migrating in an overall eastward direction at a rate up to $10 \mathrm{~m} / \mathrm{yr}$ (Héquette et al. 2008). 


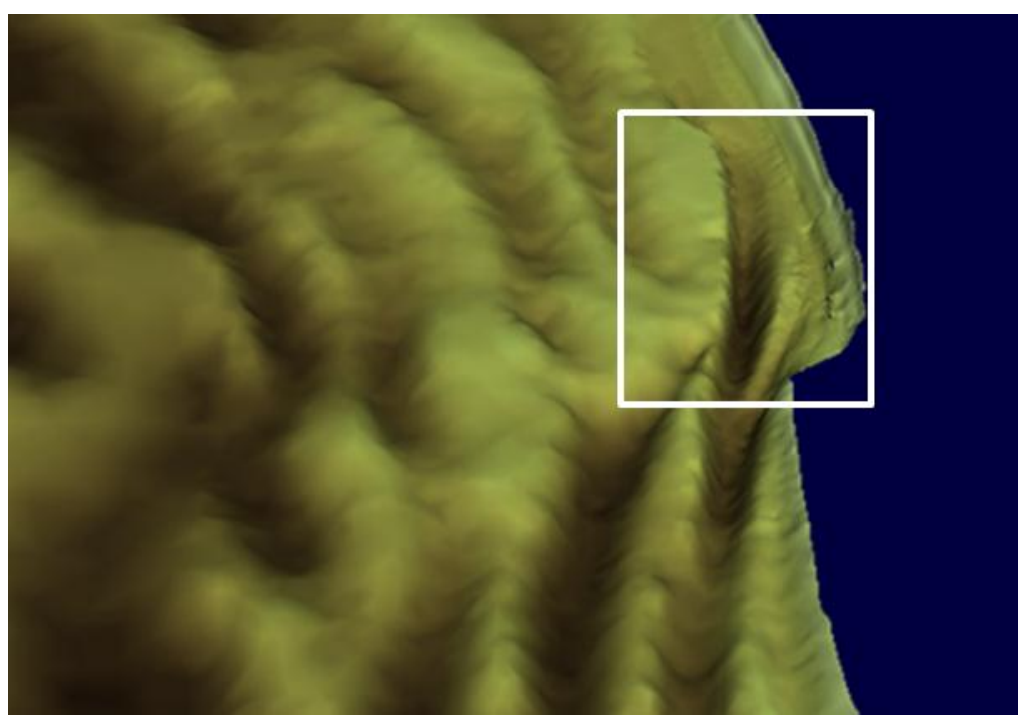

Figure 3. 3D representation of nearshore bathymetry off Dunkirk East Harbor: view from West (bottom) to East (top). The white box indicates the study site.

\section{BASELINE STUDY ON A FIXED BED}

Prior to applying a morphodynamic feedback loop in the hybrid modeling approach, a baseline study was performed based on a 2D approach on a fixed bed. This first modeling step acts as a calibration of the individual wave, flow and sediment transport modules against measured behavior, a prerequisite to the subsequent long-term modeling of shoreline predictions.

\section{Process-based 2DH modeling}

MIKE $21 \mathrm{FM}$ modules are used for the 2DH simulations of the wave, flow and sediment transport fields. No description of the applied conventional wave and flow modules is given here, as these modules are widely reported in the literature. However, a short description of the sophisticated Q3D version of the sediment transport formulation of MIKE $21 \mathrm{FM}$ is presented hereafter.

The essence of the Q3D hydrodynamics model in the sediment transport formulation is the solution of the force balance across the water column. The model calculates instantaneous and time-averaged hydrodynamics and sediment transport in two horizontal directions. The temporal and vertical variations of shear stress, turbulence, flow velocity and sediment concentrations are resolved. The time evolution of the boundary layer due to combined wave/current motion is solved by means of the integrated momentum approach of Fredsoe (1984). The force balance includes contributions from the near bed orbital motion, forces associated with wave breaking (gradients of radiation stresses) and the sloping water surface.

The depth-averaged current speed and direction as well as the wave motion defined through a number of general parameters are input parameters to the sediment transport model; these are supplied by the $2 \mathrm{DH}$ modules. The sediment transport is then simulated by a time-varying model for the suspended sediment concentration determined from the settling and the vertical turbulent exchange of the sediment and the bed load transport is determined from the instantaneous bed shear stress; see Deigaard et al. (1986).

\section{Schematization of forcing conditions}

As pointed out by Latteux (1995), a small number of tides can be found to represent the whole spring-neap tidal cycle in such a way that their cumulative effect on bed morphology is similar to the effect of the sum of all tides in the cycle. The range of the selected tide, referred to as the morphological tide, was taken as $10 \%$ larger than the mean astronomical tidal range at Dunkirk (Grunnet et al., 2004).

A wave schematization aims at reducing the wave climate into a choice of representative wave conditions. The choice of representative conditions was based on sediment transport calculations in such a way that the net transport in the study area derived from the whole climate is comparable - in intensity as well as direction - to the one deduced from the set of representative conditions. A choice of 37 representative wave conditions, each representing a directional sector including a range of wave heights and directions, was made to schematize the wave input. The selected wave conditions represent about $70 \%$ of the wave climate and approximately $90 \%$ of the transport. Each of the individual 37 wave conditions were run for the duration of the predefined morphological tide.

The wind climate was divided in classes of corresponding wave heights and directions. 


\section{Model set-up}

An unstructured flexible mesh was constructed with a relatively high resolution in the study area on the order of $5 \mathrm{~m}$. The mesh resolution gradually decreases towards the model boundaries and is as large as $250 \mathrm{~m}$ offshore and about $50 \mathrm{~m}$ along the lateral boundaries. The open sea boundary was located in water depths of approximately $20 \mathrm{~m}$. The Dunkirk model contains about 220,000 computational elements and covers an area of approximately $40 \mathrm{~km} \times 20 \mathrm{~km}$.

The boundary conditions are composed of the schematized wave conditions and the water level variations from the morphological tide. Wind forcing is applied uniformly over the model domain.

An example of the required detailed 2DH approach can be inferred from Figure 4 which illustrates wave roses along the study area: significant alongshore variability is found as a result of the strong refraction and attenuation of waves propagating over the offshore and shallow sand banks.

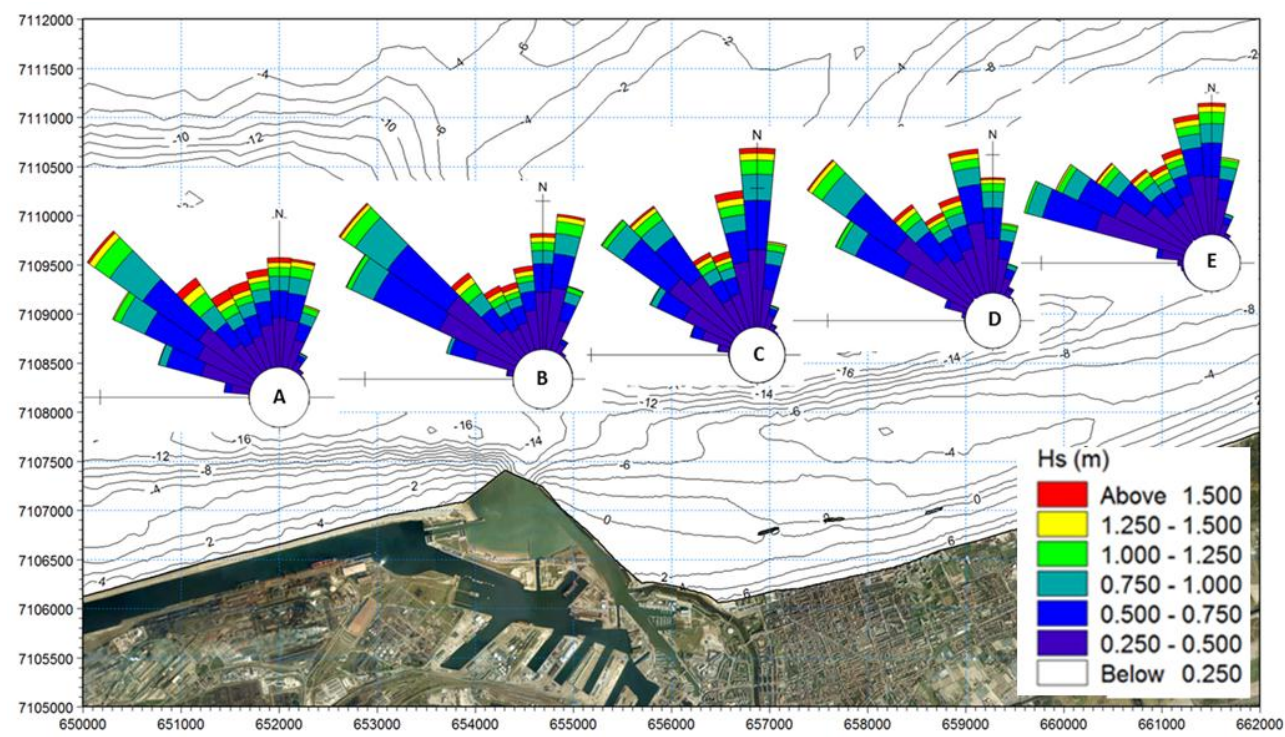

Figure 4. Alongshore variability of 1979-2002 wave roses at selected locations off Dunkirk.

\section{Calibration of the area model}

The Dunkirk fixed bed model was calibrated against a comprehensive monitoring data set comprised of hourly wave, wind, current and water level measurements, grain size data and nearshore bathymetric surveys. An overall sediment budget was established based on the detailed area modeling of waves, currents and sediment transport over a typical year as represented by the 37 selected wind and wave conditions.

The resulting sediment budget is illustrated in Figure 5. The figure shows a strong eastwarddirected net transport in the tide-dominated zone with transport rates above $150,000 \mathrm{~m}^{3} / \mathrm{yr}$. In the wavedominated zone, net transport rates are also eastward-directed; however these rates are an order of magnitude smaller and found to be below $20,000 \mathrm{~m}^{3} / \mathrm{yr}$. In general, a low morphodynamic activity in the nearshore zone is found and erosion on the order $10.000 \mathrm{~m}^{3} / \mathrm{yr}$ in front the coastal dike is confirmed.

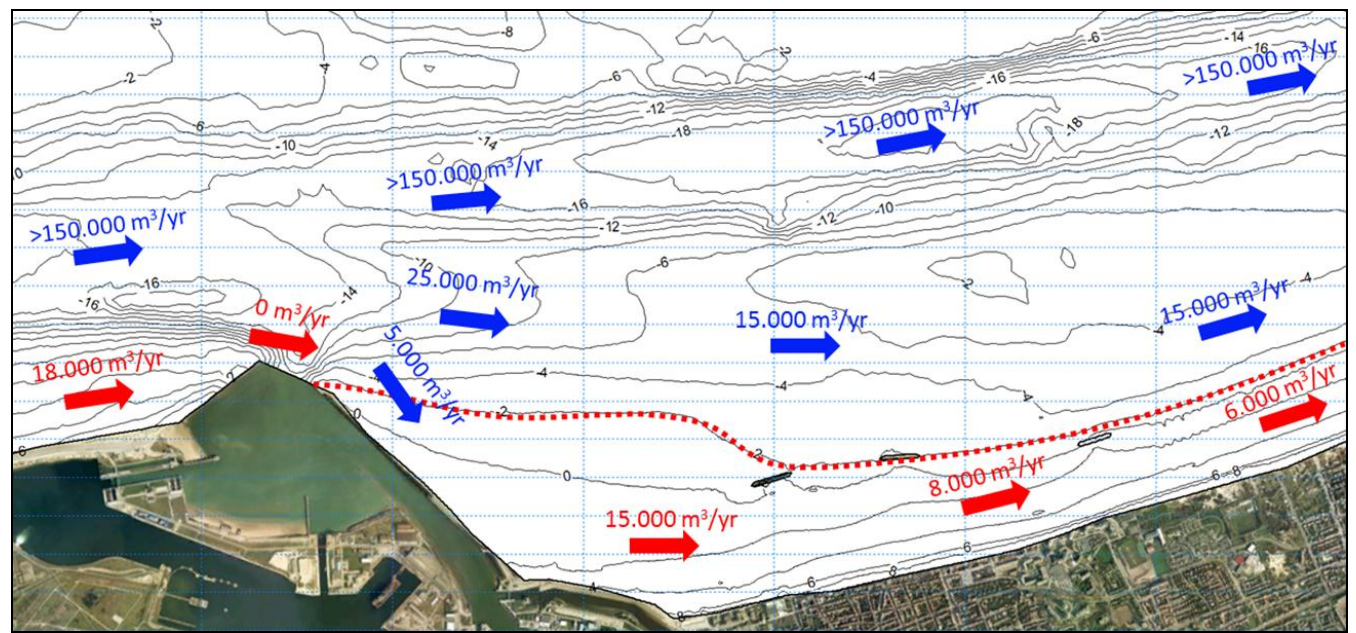

Figure 5. Average yearly net transport rates off Dunkirk. Blue (red) arrows indicate tide- (wave-) dominated net transport direction. The dotted red line indicates the seaward limit of wave action along the study site. 


\section{SET-UP OF MORPHOLOGICAL MODEL}

\section{Hybrid modeling concept}

An in-depth description of the hybrid modeling concept is given in Kristensen et al. (2010); in the following, only a brief description is given. The hybrid morphological modeling concept uses detailed two-dimensional area models to describe the wave, current and sediment transport fields. When making the morphological update the evolution of the coastal profile is restrained by allowing only one or two degrees of freedom, such as the coastline position or the volume/position of a bar. The morphological evolution is therefore based on integrated sediment transport rates and rule-based descriptions of the profile evolution. The concept thus tries to bridge the gap between existing detailed two-dimensional morphological models and simple one-line models for the coastline evolution. The primary motivation of the concept is to (1) to improve the calculated longshore transport compared to that determined by conventional 1D transport models and (2) allow simulations over longer time spans by restraining the distortion of the coastal profile which often occurs in two-dimensional models due to difficulties in making a process-based simulation of the profile evolution based on modeling of the cross-shore transport. For the present study, the morphological development is divided into two parts, namely the development of the shoreline and the development of the shoreface nourishment, each of which is further detailed in the following.

\section{Definition of shoreline model}

A linear profile is used to describe the active profile. The profile is defined in terms of a berm level, which is taken to be constant in the entire domain, a cross-shore position of the berm, a profile slope and a level of closure depth. The profile slope and level of closure depth is allowed to vary along the shoreline but is constant in time. The cross-shore position of the berm varies in both space and time. An additional parameter which defines the onshore limit of profile evolution is introduced. This parameter is used in the volume calculations of the coastal profile and allows the morphologic model to take lowering of the active height into account for profiles where extensive erosion occurs.

Best fit of the coastal profile to the measured bathymetry yield estimates of the level of closure depth, the berm position and the profile slope. The fitted estimates are used to construct the coastline parameters, and subsequently some amount of smoothing is introduced. Note that the 1D parametric description of a salient behind an existing breakwater limits the representation of the salients to a decrease in profile slope, whereas the measured salient planforms are weakly two dimensional.

The spatial resolution of the coastal morphological elements varies from 50 to $100 \mathrm{~m}$ as indicated in Figure 6. The seaward extension of the morphological grids shown in Figure 6 is selected for illustrative purposes. The actual seaward extension used in the morphological simulations follow the seaward extent of the active coastal profile. The active height of the coastal profile varies along the modeled shoreline, from $6 \mathrm{~m}$ near the harbor of Dunkerque to $10 \mathrm{~m}$ near the Belgian border located about $12 \mathrm{~km}$ to the East.

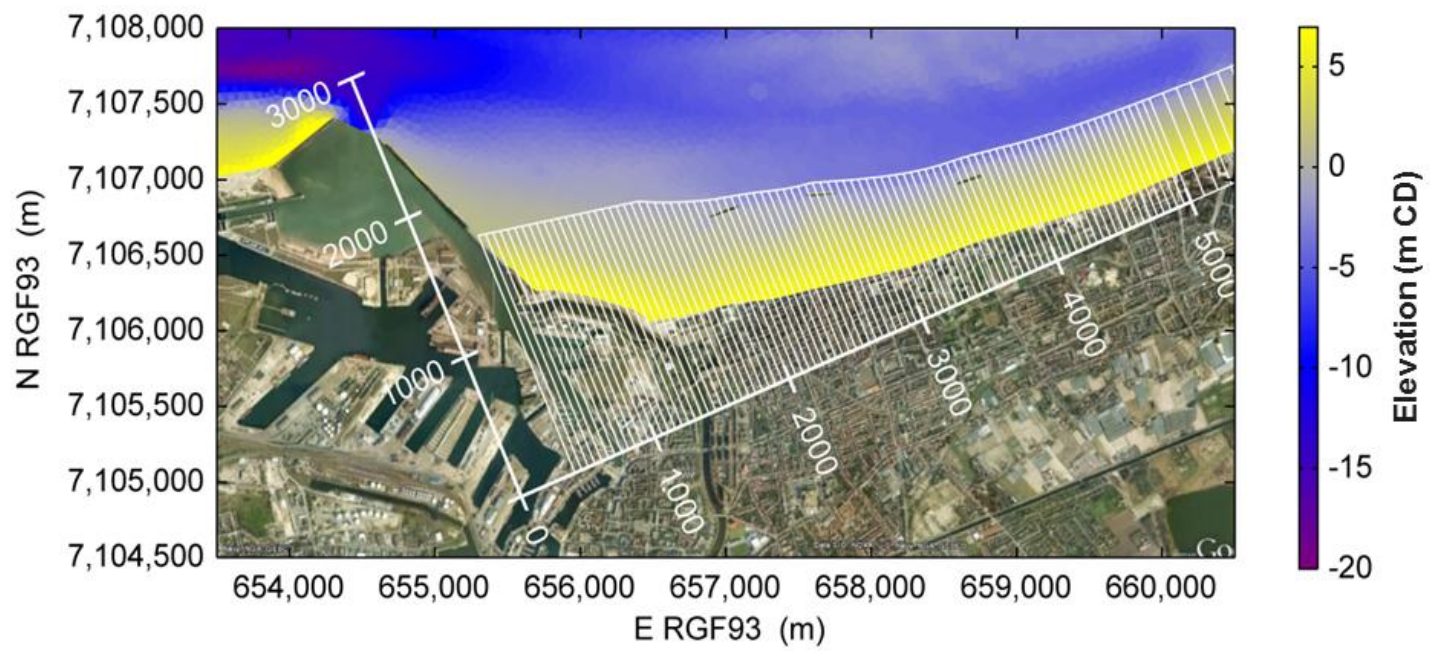

Figure 6. Morphological coastal elements are indicated with white lines (in a locally defined coordinate system) superimposed on a post-nourishment bathymetry.

The shoreline is updated by solving the 1D sediment continuity equation, where it is assumed that the coastal profile is displaced in the onshore/offshore direction in response to erosion/deposition respectively. Erosion/deposition is determined from gradients in the littoral drift and from offshore exchange of sediment which is particular important near Dunkirk harbor due to sediment bypass. 


\section{Modified littoral drift}

Separation of the longshore transport associated with changes to the upper shoreface from the transport causing morphological changes to the tidal channels and tidal banks has been difficult due to the complex bathymetric pattern in the area, the large tidal variation and significant transport in the tidal channels. A method defined here as the "Cancellation method" has therefore been applied. In the cancellation method, the littoral drift used to simulate shoreline evolution, is modeled as the difference in transport between the present shoreline and the baseline shoreline, where the baseline shoreline is represented as the shoreline prior to beach nourishment. It is therefore possible to isolate the effect of nourishment on the shoreline and thereby limit artificial shoreline change in other parts of the model which may otherwise develop when simulating shoreline change over 10 years.

\section{Model for evolution of shoreface nourishment}

Evolution of the shoreface nourishment is modeled using a bar model, where the shoreface nourishment is parameterized by defining a cross-sectional volume, a width and a cross-shore position, in sections along the shore. Morphological evolution of the shoreface parameters is imposed by use of non-linear optimization such that the development of the shoreface nourishment give a best fit to the distribution of the erosion/deposition field predicted by MIKE 21 FM.

The initial volume of the shoreface nourishment is defined invariant, and the morphological model is therefore only allowed to redistribute the nourishment alongshore and cross-shore. Transfer of sediment is however imposed for cases where the shoreface nourishment impinges to the active profile of the shoreline model, thereby feeding the shoreline with sediment and reducing the volume of the shoreface nourishment.

\section{Definition of nourishment scenarios}

The abundance of high-quality sandy sediments on site calls for a coastal protection solution based $100 \%$ on nourishment. Two types of nourishment scenarios were identified and proposed. The first is based solely on beach nourishment and the second is based on a coupling between beach and shoreface nourishment. Regardless of the nourishment scenario, suitable material for nourishment is available during the yearly maintenance dredging campaigns with borrow site grain sizes in the range 250-400 $\mu \mathrm{m}$ e.g. coarser sediments than the native sediments.

The characteristics of scenario 1 (plan view shown in Figure 7) are the following:

- Beach nourishment along and parallel to the existing dike in order to obtain the same level of protection along the dike e.g. resulting in a change of depth contour orientation of approx. $20^{\circ}$ in the study area.

- Nourishment volume of $1.500 .000 \mathrm{~m}^{3}$ distributed over $1,200 \mathrm{~m}$ with a $30 \mathrm{~m}$ wide dry beach leveled at $+7.5 \mathrm{~m} \mathrm{CD}$.

- Increased beach slope from $1 / 200$ to $1 / 70$ as a result of coarser sediment.

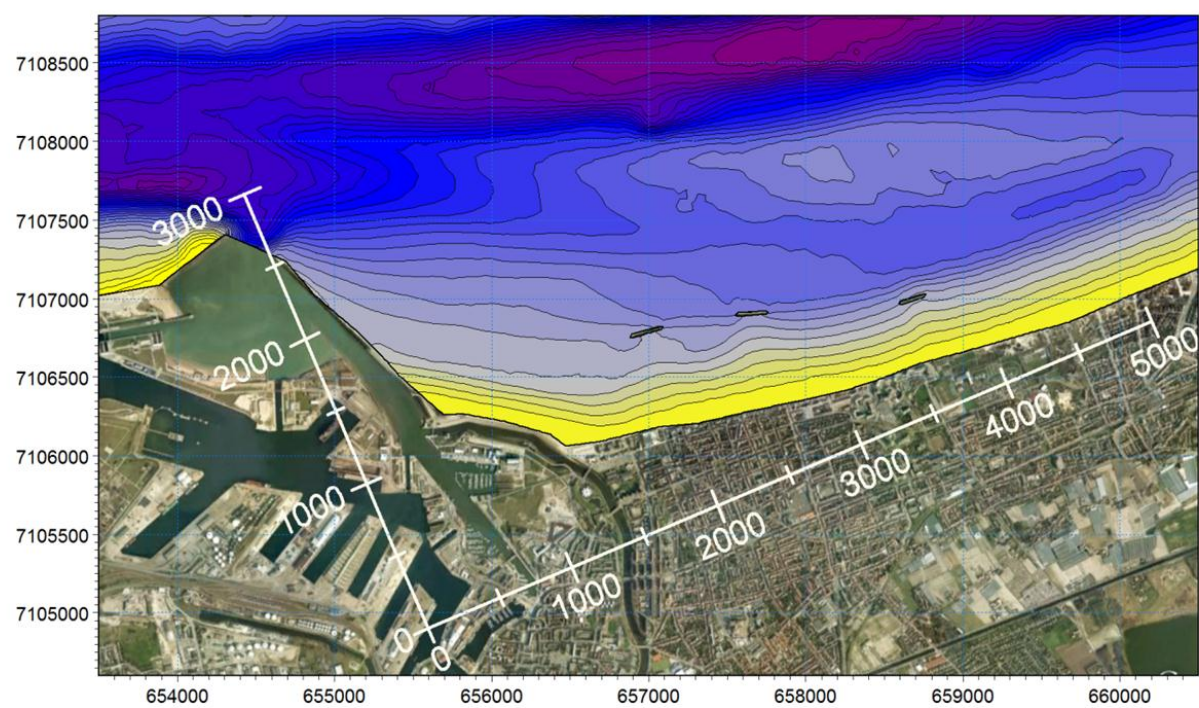

Figure 7. Post-nourishment bathymetry for nourishment scenario 1.

The characteristics of scenario 2 (plan view shown in Figure 8) are the following:

- Beach nourishment is identical as in scenario 1.

- Submerged berm located roughly between isobaths 0 and $3 \mathrm{~m} C D$ in front of dike.

- Shoreface nourishment of 700,000 $\mathrm{m}^{3}$ distributed over 1,000 m.

- Maximum height of nourished berm on the order of $4 \mathrm{~m}$. 
- $\quad$ Submerged berm located approx. $500 \mathrm{~m}$ from harbor breakwater.

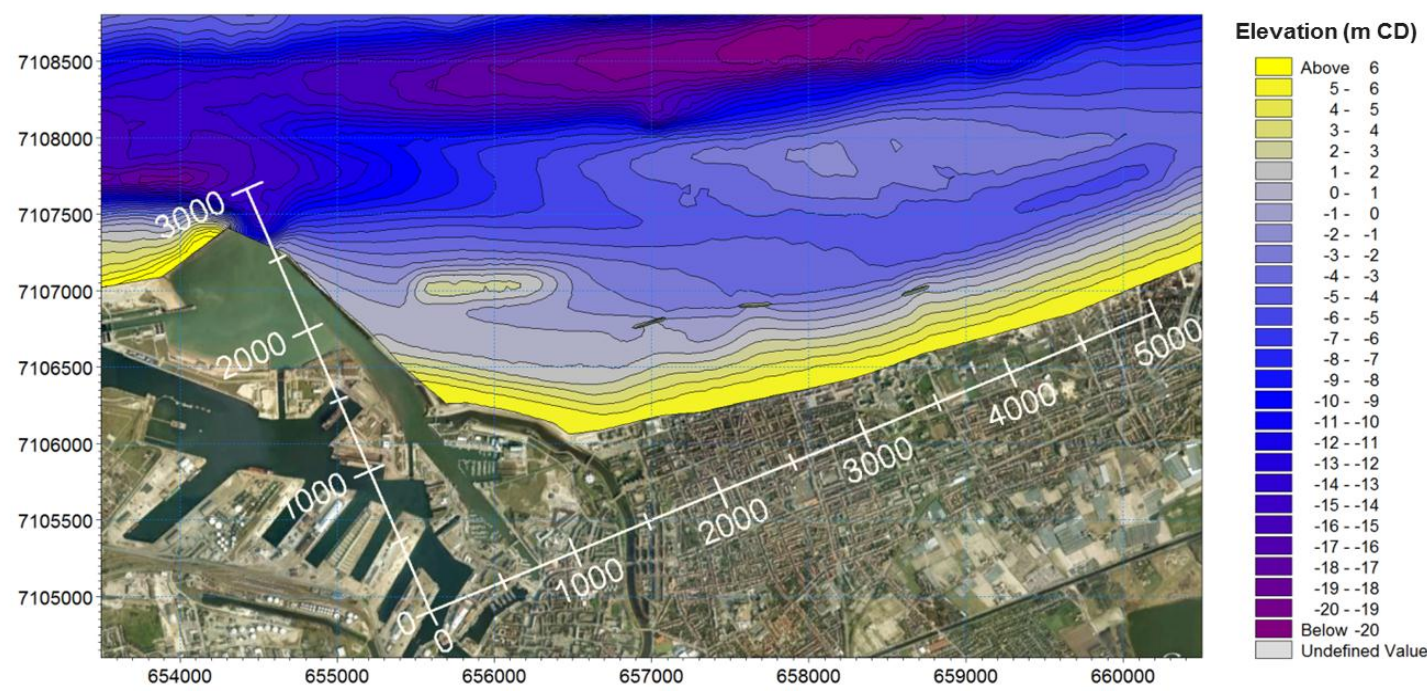

Figure 8. Post-nourishment bathymetry for nourishment scenario 2.

Although not presented in detail here, a total of five scenarios were defined, two of which are related to scenario 1 and three of which are related to scenario 2 . The additional scenarios only differ by their geometric characteristics such as berm location and height and suggested maintenance schemes for the beach nourishment solution.

\section{SIMULATION OF MORPHOLOGICAL RESPONSE}

The hybrid modeling approach was used to simulate the morphological response of the various nourishment scenarios. A simulation period of 10 years was selected for all predictions of morphological development. All results shown hereafter are relative to the actual situation: recall that the previously defined "cancellation method" implies that the natural background morphological behavior has been removed from all computations. Hence the results here show the relative impact of the nourishment solution. In the following, results are firstly shown individually for the two types of scenarios and secondly compared.

\section{Beach nourishment alone}

The bathymetric evolution after 10 years of morphological modeling is presented in Figure 9 for nourishment scenario 1. The characteristics of the morphological impact are the following:

- Erosion of the western half of the nourished beach with a seabed lowering up to of $0.5 \mathrm{~m}$.

- Accretion of the downdrift beaches to the east with a seabed rise up to $0.5 \mathrm{~m}$.

The morphological evolution for scenario 1 thus consists in a dynamic response towards a new equilibrium by which a change in orientation of the nourished beach occurs.

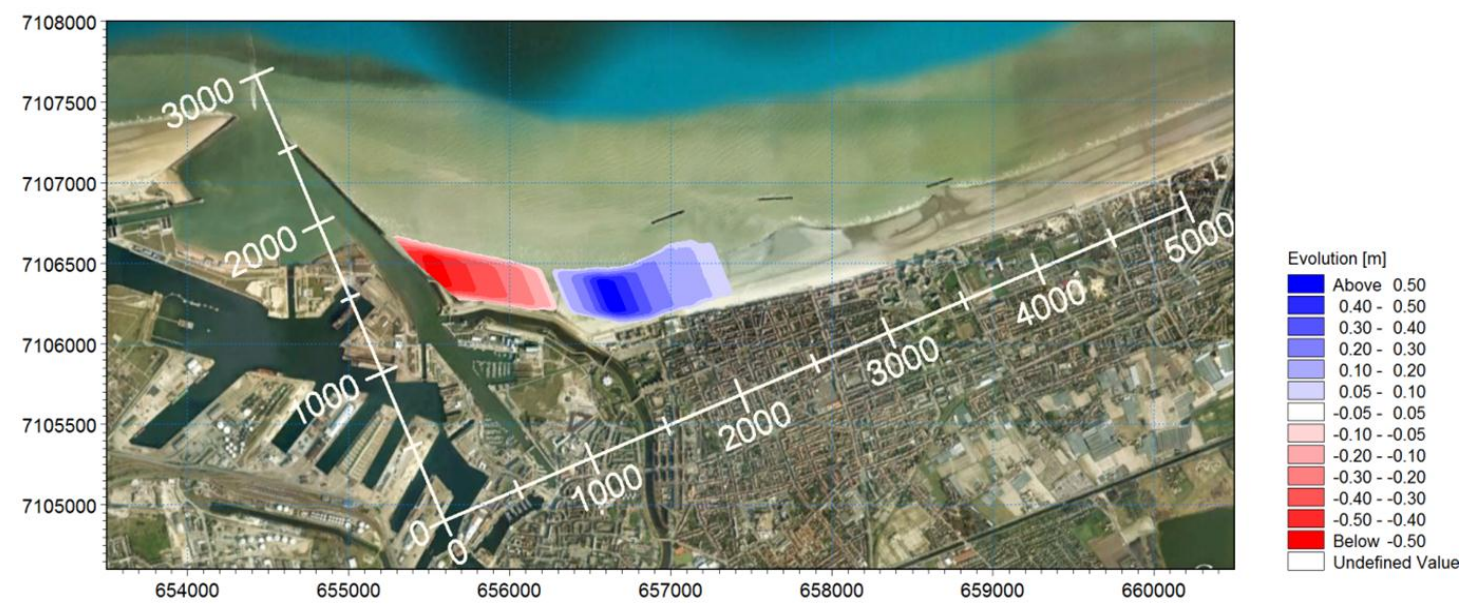

Figure 9. Morphological response after 10 years of simulation: bathymetric evolution for scenario 1. 


\section{Beach and shoreface nourishment coupled}

The bathymetric evolution after 10 years of morphological modeling is presented in Figure 10 for nourishment scenario 2 . The characteristics of the morphological impact are the following:

- Attenuated erosion of the western half of the nourished beach with a seabed lowering reduced to less than $0.4 \mathrm{~m}$.

- Attenuated accretion of the downdrift beaches with a seabed rise less than $0.4 \mathrm{~m}$.

- Moderate erosion of the beaches in the breakwater area with a seabed lowering up to $0.05 \mathrm{~m}$.

- Onshore and alongshore migration of the shoreface nourishment (very strong migration the first 2-3 years after implementation).

- Perturbation of tidal channel dynamics to the north-east of the nourished berm.

The morphological evolution for scenario 2 thus consists in (1) an attenuated response towards a new equilibrium by which a change in orientation of the nourished beach occurs, (2) a rapid migration of the nourished berm, and (3) a moderate erosion of the beaches further downdrift - note that with an average slope of approximately $1 / 70$, a seabed lowering on the order of $0.05 \mathrm{~m}$ corresponds to a shoreline retreat of $3.5 \mathrm{~m}$ in 10 years.

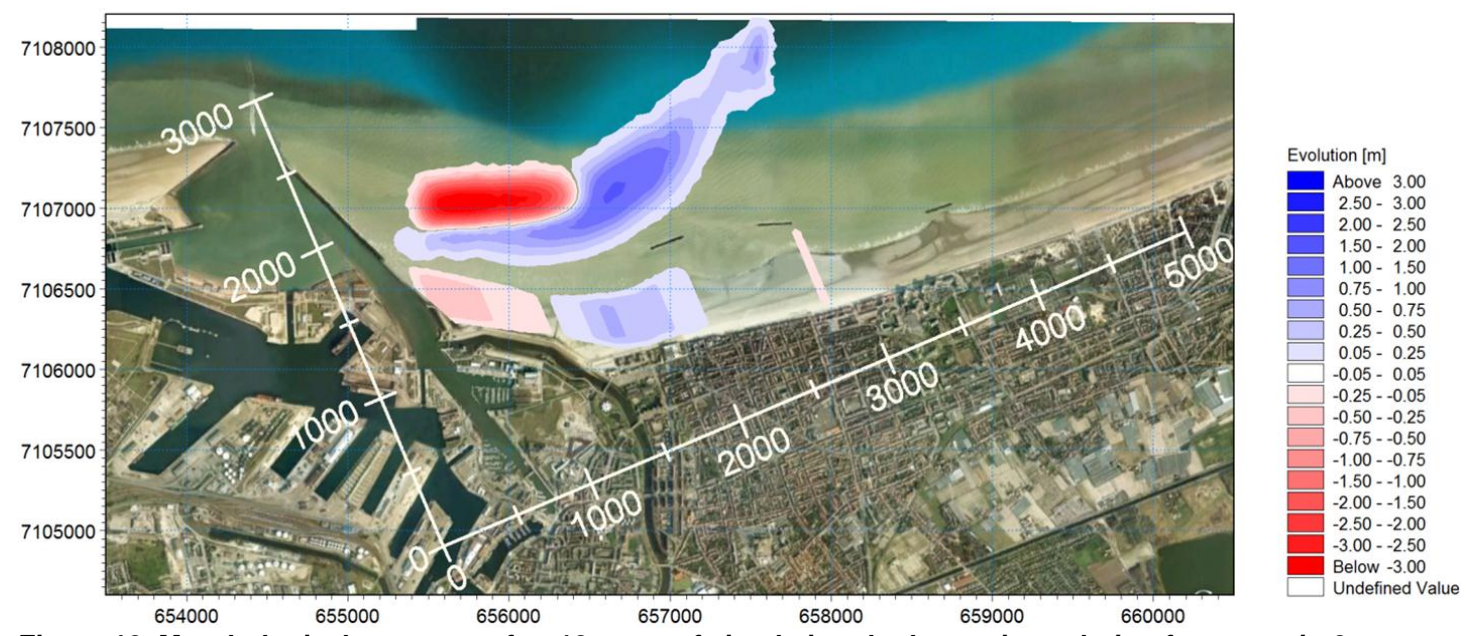

Figure 10. Morphological response after 10 years of simulation: bathymetric evolution for scenario 2.

\section{Comparison of nourishment scenarios}

A comparison of the five modeled nourishment scenarios is given hereafter, however only impacts of scenario 1 and 2 are reported here. The comparison is based on the spatial and temporal evolution of the littoral drift immediately after the implementation of the nourishment and after 10 years of evolution. The analysis covers the coastal stretch impacted by the nourishment e.g. a few kilometers east of the harbor breakwaters. Note that in the applied local coordinate system, the coastal dike is located between 400 and 1,400 $\mathrm{m}$ from the origin.

The positive and negative impacts are significant immediately following the implementation of the various nourishment schemes (see Figure 11):

- Increased littoral drift for both scenarios as a result of the new shoreline orientation e.g. erosion of the nourished beach on the order of $10,000 \mathrm{~m}^{3} / \mathrm{yr}$ and subsequent increased downdrift supply.

- Deposition on the order of $10,000 \mathrm{~m}^{3} / \mathrm{yr}$ immediately downdrift of the nourishment for both nourishment scenarios.

- The shoreface nourishment decreases the littoral drift east of the dike $(2,000$ to $3,000 \mathrm{~m})$ due to the breakwater effect of the submerged berm.

After 10 years of morphological evolution, the positive and negative impacts of the nourishment scenarios are attenuated (see Figure 12):

- Continuous erosion of the nourished beach, however at slower rate reduced to approximately $6,000 \mathrm{~m}^{3} / \mathrm{yr}$.

- Downdrift beach tends towards a new equilibrium, leading to a reduction in transport gradients in this coastal stretch.

- Continuous eastward propagation of negative impact of the shoreface nourishment. 


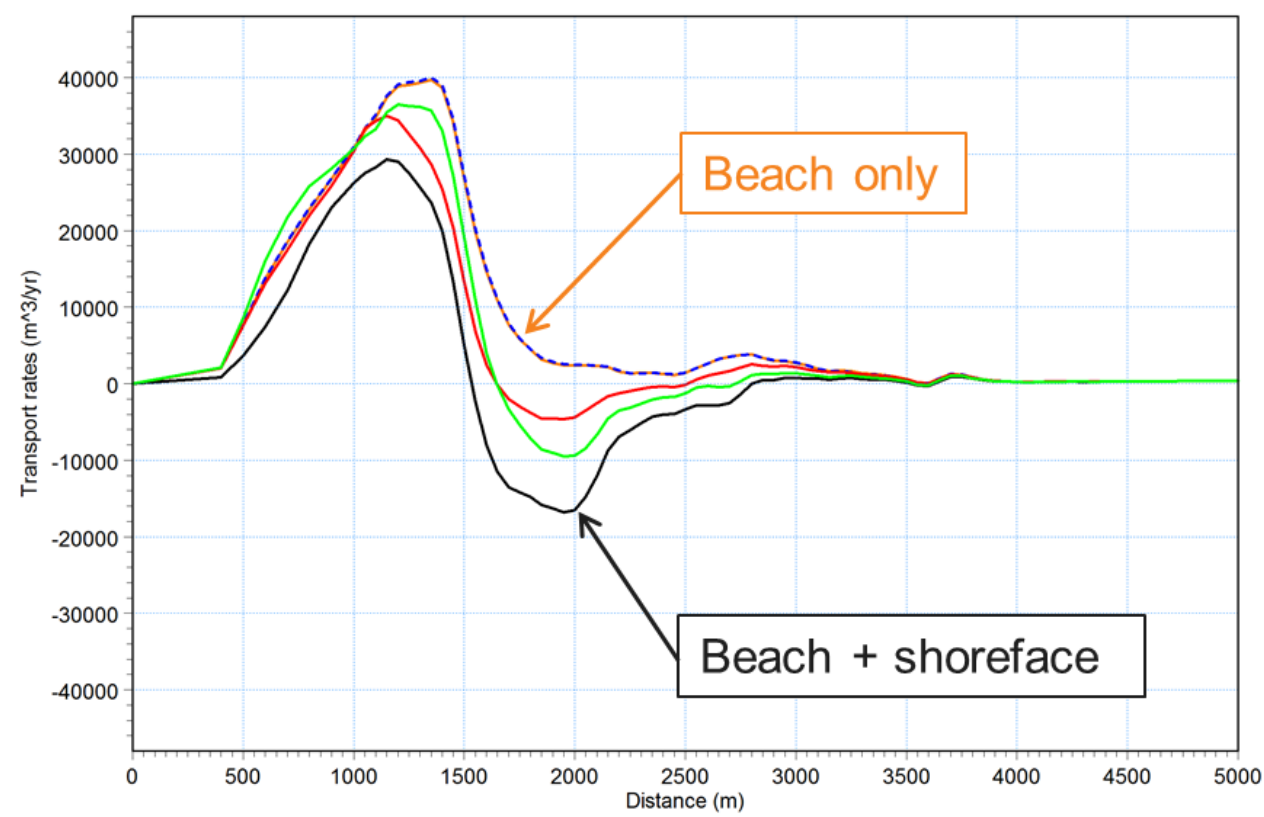

Figure 11. Littoral drift immediately after implementation of nourishment scheme for various nourishment schemes $(t=0$ year); nourishment scenarios presented in this paper are highlighted. Positive (negative) transport corresponds to increased (decreased) littoral drift with respect to pre-nourishment situation.

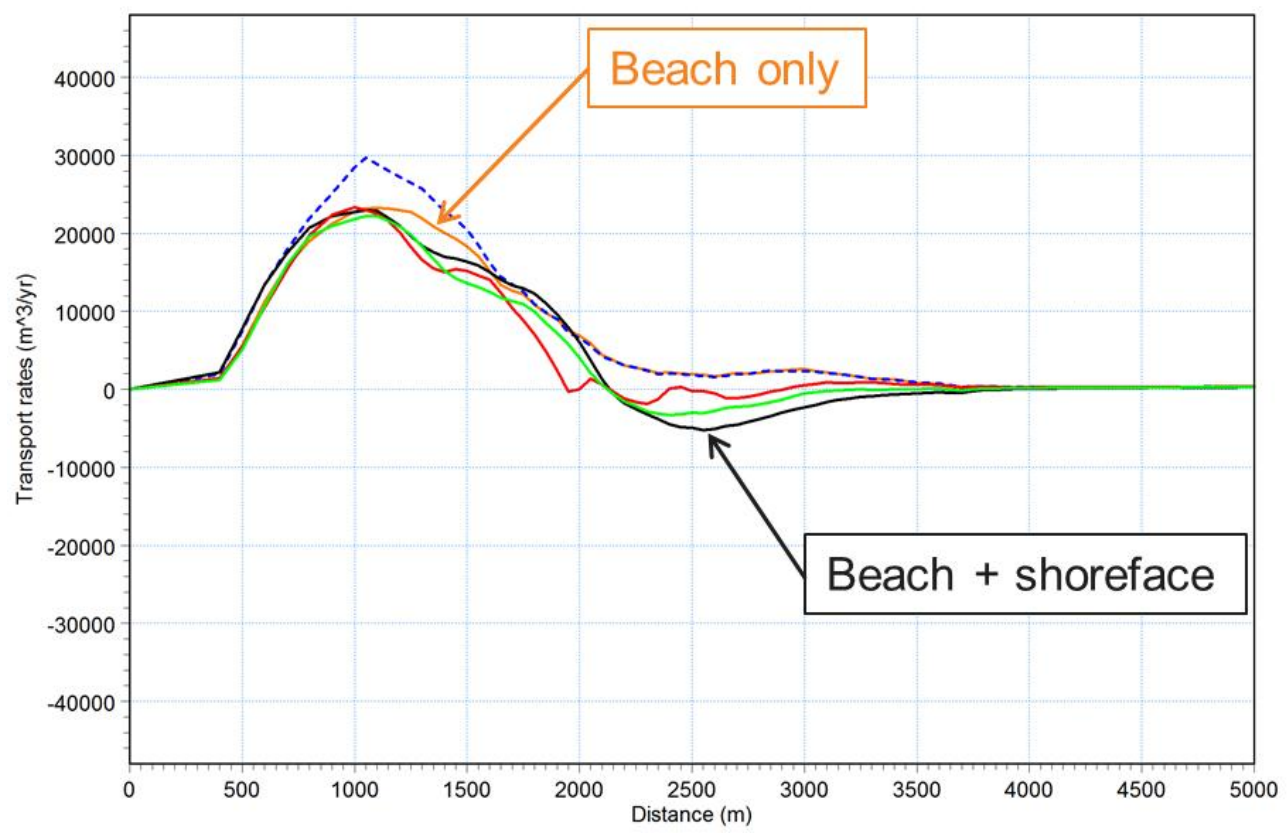

Figure 12. Littoral drift 10 years after implementation of nourishment scheme for various nourishment schemes ( $t=10$ years); nourishment scenarios presented in this paper are highlighted. Positive (negative) transport corresponds to increased (decreased) littoral drift with respect to pre-nourishment situation.

The evolution of the nourishment volume in its initial location was also investigated in order to define the required volume necessary to maintain the initial level of protection of the coastal dike constant throughout a 10-year period. An illustration of this evolution is presented in Figure 13. The figure clearly shows the significant erosion of the shoreface nourishment caused by the rapid migration of the submerged berm. Hence, the level of protection supplied by the shoreface nourishment decreases rapidly in time and the order of magnitude for maintenance nourishment is above 100,000 $\mathrm{m}^{3} / \mathrm{yr}$, specifically in the first years. On the opposite, a moderate and gradually decreasing erosion of the beach nourishment is observed: maintenance nourishment is on the order of $40,000 \mathrm{~m}^{3} / \mathrm{yr}$ and decreasing with time.

Based on these results, the pure beach nourishment solution was selected for implementation. 


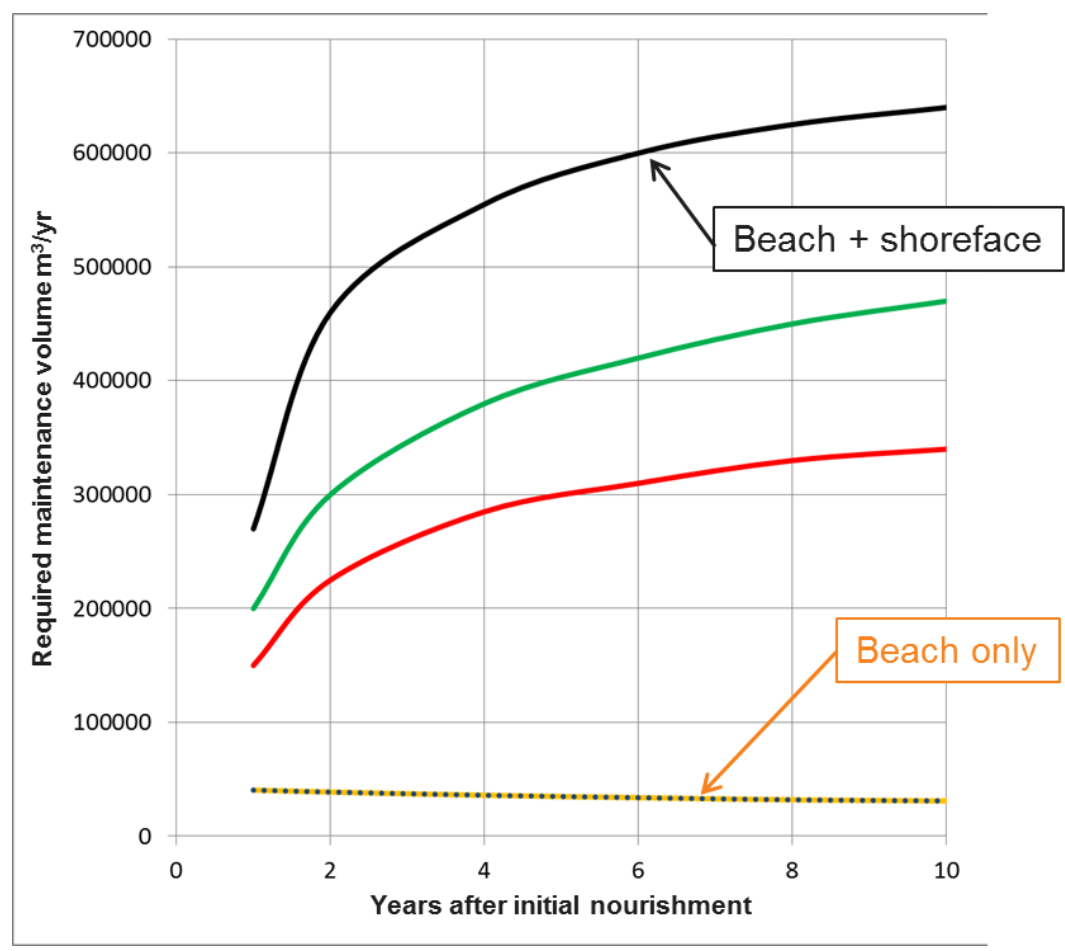

Figure 13. Required maintenance volume to maintain the initial level of protection of the dike.

\section{CONCLUSIONS}

The hybrid model was successfully applied to predict the 10-year morphologic evolution of individual beach and shoreface nourishment projects as well as a combination of these. The morphological modeling conclusively showed that shoreface nourishment is not suited for the present site as (1) the migration of the berm interacts with the tidal channels, (2) the downdrift supply of sediment decreases, and (3) the required volume to maintain the initial level of protection increases in time. Beach nourishment was consequently selected as the preferred solution as (1) it evolves at a slower rate, (2) increases the downdrift supply of sand, and (3) does not perturbate the background morphological system.

This study strongly indicates that the hybrid model may be used as an engineering tool to predict shoreline response following a nourishment project. The selected nourishment project e.g. the beach nourishment alone, will be fully implemented in 2012 during the yearly fall maintenance dredging campaigns. A monitoring program has been scheduled to follow the morphological evolution of the nourishment.

\section{AKNOWLEDGEMENTS}

Dunkirk Harbor is acknowledged for entrusting DHI to apply a research version of the hybrid model concept for this study. The second author was granted a leave of absence from his ph.d. study at the Technical University of Denmark, to participate in application and further development of the hybrid modeling concept to the nourishment schemes in Dunkirk, France.

\section{REFERENCES}

Deigaard, R., Fredsoe, J. and Hedegaard, I.B., (1986), Mathematical Model for Littoral Drift, Journal of Waterway, Port, Coastal and Ocean Engineering, Volume 112, Issue 3, 351-369, ASCE

Drønen, N., Kristensen, S., Taaning, M., Elfrink, B. and Deigaard, R., (2011), Long term modeling of shoreline response to coastal structures, Proceedings of Coastal Sediments, ASCE, 965-978.

Fredsoe, J., (1984), Turbulent boundary layer in wave-current motion. Journal of Hydraulic Engineering, 110 (8), 1103-1119.

Grunnet, N., Walstra, D.J.R. and Ruessink, B.G., (2004), Process-based modeling of a shoreface nourishment, Coastal Engineering, Volume 51, Issue 7, 581-607.

Héquette, A., Hemdane, Y. and Anthony, E.J., (2008), Sediment transport under wave and current combined flows on a tide-dominated shoreface, northern coast of France, Marine Geology, 249: 226-242. 
Kristensen, S., Deigaard, R., Taaning, M., Fredsoe, J., Drønen, N. and Jensen, J., (2010). Long term morphological modeling, Proceedings of the $32^{\text {nd }}$ International Conference on Coastal Engineering, ASCE, Shanghai, China, ISSN 2156-1028.

Kristensen, S.E., Deigaard, R., Drønen, N., Fredsoe, J. and Luger, S., (2012), Morphological modelling of the response to a shipwreck - a case study at Cape Town, Proceedings of the $33^{\text {rd }}$ International Conference on Coastal Engineering, ASCE, Santander, Spain.

Kristensen, S.E., Drønen, N., Deigaard, R. and Fredsoe, J. (2013a), Hybrid morphological modelling of shoreline response to a detached breakwater, Coastal Engineering, 71:13-27.

Kristensen, S.E., Drønen, N., Deigaard, R. and Fredsoe, J. (2013b), Hybrid morphological modelling of the response to groyne fields, Intended for publishing in Coastal Engineering.

Latteux, B. (1995), Techniques for long-term morphological simulation under tidal action, Marine Geology, 126:129-141. 